\title{
Managerial Skills in Chinese State-owned Corporations
}

\author{
Ziguang CHEN and Mitsuru WAKABAYASHI \\ (The Graduate School of International Development, Nagoya University)
}

\begin{abstract}
Recently, many Chinese state-owned corporations (SOCs) have started to change the traditional management system into the morden one. As a result, the quality of managers in SOCs has increased and their performance has improved. In this study, an effort was made to find ten most important skills for managers in Chinese SOCs: (1) that characterise their present level of managerial performance, (2) that are required for improving their managerial performance on the present job, and (3) that will be critical for Chinese managers to function effectively under the market economy situations. The results identified the common seven skills across these three different situations: namely skills of strategic thinking, profit consciousness, proper use of personnel, decision making, quality control, motivating, and innovativeness, but with a different order of importance for each situation. However, in different situations, some additional different skills were found important. In summary, most of the top ten skills were found to belong to the category of organizational development capabilities. Some differences that were found between different managerial levels and between high and low performing SOCs were discussed.
\end{abstract}

\section{INTRUDUCTION}

Since China started the economic reform and the open door policy in late 1970 s, the management system of Chinese state-owned corporations (SOCs) has made steady progress through 1980s and early 1990s (Brown and Branine, 1995; Chen and Wakabayashi, 1996; Zhong, 1993; Li, 1996; Sun and Wakabayashi, 1992). A strategy plan was proposed in the 14th Council's 5th Meeting of the Central Committee of China's Communist Party in 1995 for deepening the reform and establishing the foundation of a modern system of management of SOCs for the coming 15 years (The Central Committee of China's Communist Party, 1995). Since 1995, the reform of SOCs has been identified as a core of the national economic system reform in China. After reviewing historical development of Chinese administrative behavior research, Wakabayashi and Zhen (1995) pointed out that for the purpose of promoting the current China's socialist market economic policy, China needs to promote research on: (1) how to develop internal HRD systems, (2) how to implement organizational development programs unique to the
Chinese tradition, (3) how to develop decentralized decision making structure in the organization by creating participative leadership, and (4) how to create new corporate culture independent of, but compatible with, Chinese national culture and ideology of socialism.

Recently, a great number of Chinese SOCs have experienced changes in the traditional management policies especially those of personnel managemant under the label of 'HRM' (Brown and Branine, 1995; Chen and Wakabayashi, 1996). Many rescarchers have commented about different aspects of these changes, such as the labor law (Zheng, 1987), the labor contract system (White, 1987), wage, bonus and benefit (Wu and Chen, 1992; Hu et al., 1988; Guanghaw, 1985), labor allocation (White, 1982), labor relations (Litter and Lockett, 1983; Lee, 1986; Warner, 1991; Chen, 1993 b), management decisions (Child, 1987, 1991, 1994; Child and Lu, 1990; Lu and Child, 1994; Wang, 1989; Chen and Wakabayashi, 1996), management development and traning (Warner, 1985, 1987, 1992; Brown and Jackson, 1991), employment policies (Han and Morishima, 1992; Chen, 1993a), and the cognitive processes of people's responses 
to the organizational change (Bartunek, Lacey and Wood, 1992; Lau, 1995).

It is obvious that organizations need to maintain practices which are consistent with the overall business strategy in order to remain competitive in the global market (Caligiuri and Stroh, 1995). On the other hand, managers in Chinese SOCs are doing their job mainly within the changing domestic environment. Theoretically speaking, managerial methods should be based on how managers perceive the environmental changes inside and outside the organization. What is particularly important is the management perception on required knowledge and skills to cope with the changing environment. The sound managerial HRD policy can be developed on the basis of the recognition of what are the required knowledge and skills for managers. However, a little has been reported regarding how Chinese managers in SOCs recognize their managerial skills needed in order to meet the changes in the present environment, the developing socialist market economy in China. Wise and Fen (1988) pointed out that there would be three major skill clusters: skills for strategic and tactical management, information and resource management, and performance and people management. In their survey, topperforming managers at all levels saw planning, organizing, monitoring, delegation, and managing / appraising performance as tasks that would be critical for effective managerial performance in the future. They emphasized four skills to be the 'core' ones: (1) problem analysis and decision making, (2) oral commnucation skills, (3) writing skills, and (4) interpersonal skills including listening, resolving conflict, collaborating, negotiating, and managing by influence.

This paper focuses on identifying critical ten managerial skills for development of the internal HRD system for managers in Chinese SOCs. The objectives of this research are: (1) to find out ten most important skills which Chinese managers are now practicing, (2) ten most needed managerial skills for improving the present level of performance of focal managers, and (3) to identify ten managerial skills which will become most important for developing socialist market economy in China. In addition, statistical analyses will be conducted to test the differences among the top, middle and lower-middle managers, and between the managers in high and low performing Chinese SOCs, regarding the degree of importance that managers in each category attach to the ten managerial skills chosen.

\section{METHOD}

\section{1) Subjects}

Twelve state-owned corporations with different sizes were surveyed in two cities (Hangzhou and Shaoxing) in Zhejiang Province, China. Subjects consisted of managers representing across three management levels, namely top, middle and lower-middle levels. The top managers consisted of directors and vice-directors, while the middle managers consisted of section managers, and the lower-middle managers consisted of assistant section managers of workshops and sections (e.g., personnel, reasearch and development, technology, sales, and administration sections). Prior to the administration of the questionnaire survey, objctives of the research were discussed with the top managers of sample SOCs in order to win their understanding and support. During the survey period, all managers in the sample corporations ranging from the top to the middle and lowermiddle managerial levels were asked to respond the questionnaire. In total, 218 managers in 12 SOCs were asked to fill out the questionnaires. Among them, 8 questionnaires could not be used due to the incomplete responses. Thus, the final number of subjects used for the present analysis remained to be 210, with the respondents' age ranging between 24 and 61 , and including 52 top managers, 99 middle managers and 59 lowermiddle managers. Among them, 147 are male and 63 are female managers.

\section{2) Measure}

Two sets of questionnaires were used: one for the top managers, and the other for the middle and lower-middle managers. Both of the questionnaires contained the same contents, but with 
slightly different instructions between the two.

All questionnaires contained 37 managerial skill items (see Appendix). In the questionnaire, (1) all sample managers were asked to choose five managerial skills in order of importance (out of the 37) that they expect to be the most important for Chinese managers to function effectively under the market economy business environment. (2) The top managers were asked to choose, in order of importance, the five most important skills that they possess now. On the other hand, the middle and lower-middle managers were asked to choose five most important skills that their immediate superiors are now practicing. Finally, (3) the top managers were asked to choose five most needed skills which are required for improving their present level of managerial performance. Likewise, the middle and lower-middle managers were asked to choose five most needed skills which their immediate superiors are required to have for improving their present level of managerial performance. It should be pointed out that for this study, the five most important managerial skills denotes those now possessed and needed for the superior of the sample managers. This form of question was devised in order to give a clear (objective) benchmark to the respondents in choosing the five most important managerial skills, instead of asking to pick up five important skills which the respondent managers believe to be important subjectively. However, the top managers have no superiors within the organizations, thus they were asked to choose five important skills for themselves.

For the purpose of testing a difference between the managers in high and low performing SOCs, the average annual wage level of employees within the corporation was used as an index for the high vs. low classification. Prior to the sampling of SOCs for the survey, a series of interviews with the local government bureau in charge of supervising each SOC were conducted. If the average annual income of employees in the corporation exceeded 8,000 Yuan (RenMinBi), then that corporation was classified into the high performing SOC group, otherwise it was classified into the low performing group. Based on this criterion, 4 SOCs sampled for this survey were identified to be the high performing SOCs, while the other 8 SOCs to be the low performing SOCs. To use the average annual wage level as an approximation to corporate performance can be made plausible by the following reason. Namely, the annual wage in Chinese SOCs is a combination of the basic salary set at the low, subsistence level, and bonus distributed in greater variation reflecting the corporation's paying ability. This means that unless a SOC can keep the substantial amount of after-tax profit, i.e., high performance, only a little resource would be left available for distributing bonuses among employees. On the other hand, a high profit making SOC can afford to give out a greater portion of after-tax profit to its employees without being bothered by the burden of allocation in the form of stock dividend. Therefore, the average annual wage consisting of a combination of low basic salary and widely varying bonus can be a good approximation to the corporation's business performance, since the financial data of the SOCs being not disclosed publicly in China.

\section{RESULTS}

\section{1) Ten most important skills now practiced by managers in Chinese SOCs}

It is said that the management practices have been improved in Chinese SOCs in recently years, due to the increase of qualified managers. Chen and Wakabayashi (1996) found that the percentage of college graduates among top managers surveyed in their study is $75 \%$ in Chinese SOCs. Also, a survey conducted by the Chinese Entrepreneure Investigating System (1996) found that the percentage of college graduates is $79.6 \%$ out of 2674 top managers randomly sampled in the local business community in China (People's Daily Overseas Edition, 1996, 4, 22). However, a question remains regarding on what kinds of managerial skills, the managers in Chinese SOCs are relying for managing their corporations?

To answer the above questions, in our study managers in SOCs were asked to choose five important managerial skills in order of 
Table 1 The first 10 most frequently cited managerial skills now practiced by Chinese managers in SOCs, chosen in order of importance (from rank 1st to 5 th) for characterizing their present level of job performance $\mathrm{N}=210$

\begin{tabular}{l|c|c|c|c|c|c|r|r}
\hline \hline \multirow{2}{*}{ No. Skill } & \multirow{2}{*}{$\begin{array}{c}\text { Overall } \\
\text { Ranking }\end{array}$} & $\begin{array}{c}\text { Overall } \\
\text { Fre- } \\
\text { quency }\end{array}$ & $\%$ & \multicolumn{4}{|c|}{ Frequencies by Importance Rank } \\
\cline { 5 - 9 } & 1 & 97 & 46.2 & 79 & 10 & 0 & 6 & 2 \\
\hline 1 Strategic thinking & 2 & 80 & 38.1 & 9 & 14 & 11 & 29 & 17 \\
31 Profit consciousness & 3 & 78 & 37.1 & 12 & 18 & 12 & 7 & 29 \\
37 Proper use of personnel & 4 & 65 & 31.0 & 30 & 18 & 12 & 4 & 1 \\
3 Decision making skills & 4 & 55 & 26.2 & 2 & 5 & 26 & 14 & 18 \\
32 Quality control & 5 & 47 & 22.4 & 1 & 23 & 9 & 9 & 5 \\
7 System development & 6 & 46 & 21.9 & 4 & 9 & 11 & 9 & 13 \\
15 Motivating skills & 7 & 41 & 19.5 & 8 & 17 & 7 & 6 & 3 \\
4 Innovativeness & 8 & 35 & 16.7 & 15 & 6 & 8 & 2 & 4 \\
5 Planned actions & 9 & 32 & 15.2 & 1 & 6 & 4 & 8 & 13 \\
26 Integrity & 10 & 32 &
\end{tabular}

importance ranging from the most important (1st) to the fifth important (5th). Table 1 shows frequency distribution for ten most important managerial skills that sample managers selected as being now practiced by their superiors to keep the present level of performance in Chinese SOCs.

(1) Strategic Thinking that is explained in the questionnaire as a skill to consider market situations, competitors, future goals and long-term company prosperity when making decisions, turned out to be the most important skill now practiced by managers in Chinese SOCs as shown in Table 1. Namely, $46.2 \%$ out of 210 managers have chosen this skill as one of the five most important skills practiced now by their superiors to maintain their present level of job performance. Before the start of economic reform, China has implemented planned economy long time throughout the country. During that time, managers especially top managers in SOCs had little power to control their corporations through their own ideas and methods. What they should do was decided by the central govenment already. Since China started the economic reform, however, especially since the introduction of socialist market system in 1992, the situations have changed dramatically. Managers now have to decide almost everything related to the company operations. Especially, the strategic thinking skill regarding how to develop the organization for survival and success under the increasing market competition and how to set long-term corporate objectives, became critically important for top managers in SOCs.

(2) Profit Consciouseness means a skill to set the profit targets, and stressing the cost-saving and profit-making behaviors. Table 1 shows that the skill of profit consciouseness was found the second most important (38.1\%) for managers in SOCs. For them one of the main objectives to accomplish for SOCs is to make profit, otherwise the corporations could not survive over time, particularly in the world of market economy. If a corporation can not achieve the profit objective, it will impact on its employee's salary and bonus, job satisfaction, and work motivation. This in turn affect productivity and corporate profit negatively. This vicious cycle is fatal for the Chinese SOCs that are under the transition from a seller's market to a buyer's market. Thus, it is reasonable that the skill of profit consciouseness was given a special attention by the managers as being practiced now by their superiors. A statistical analysis for testing differences between 
managerial levels showed that there are significant differences in choosing the important skills between the top and middle managers $(\mathrm{Z}=2.33$, $P<.05$ ), and between the top and the lower-middle managers $(Z=2.33, P<.05)$ involving the profit consciouseness. These results indicated that the middle (42.4\%) and lower-middle (44.1\%) managers chose the skill of profit consciouseness to be more important than did the top managers (23.1\%). Also, a comparative analysis indicated that the percentage of choosing the skill of profit consciouseness is lower in high performing corporations (24.1\%) than in low performing ones (42.9\%, $\mathrm{Z}=2.45, \mathrm{P}<.05)$. It could be that in high performing corporations, managers tend to think their company has achieved high profit already, so the profit priority becomes lower, while in low performing corporations profit consciouseness is given higher priority.

(3) Proper Use of Personnel is explained in the questionnaire as a skill to choose the right person for the right job based on the accuarte assessment of each subordinate ability. Overall, this skill represents the third important one (37.1\%). One of the weaknesses in Chinese management pracrices is an excessive concern with people and human relations. It often happens that an important position is filled by a person with little skills but having close relationship with a top manager. This biased personnel practice has hindered to give full play to competance of talented people who has little private relationships with the top management. Heller (1989) pointed out that there is a significant positive correlation between a person's job satisfaction and utilization of his competance. Then, a skill for the proper use of personnel should enable the Chinese managers to utilize subordinates' abilities maximally and to maintain their job satisfaction at the high level.

(4) Decision Making Skill denotes in the questionnaire to be a skill for making timely decisions under uncertainty and risk-involved situations. The socialist market economy has created a situation of uncertainty and risk-involvment for the managers in Chinese SOCs. They must deal with more unfamiliar situations for developing corporations than they did under the central planned economy. They started to pay more attention to enhance their decision making skills recently. It is said that the decision making skill of managers in Chinese SOCs has improved since the economic reform. For example, research results showed that the participative decision making system had very positive effects upon management behavior, and that the average level of participative decision making was higher in China than similar studies in other countries (Wang, 1989). In our study, the decision making skill is ranked the 4th important (31.0\%) one. An analysis on the frequency of choosing decision making as the most important skill showed a significant difference between the top (23.1\%) and lowermiddle (42.2\%) managers $(\mathrm{Z}=2.15, \mathrm{P}<.05)$. This result suggests that the lower-middle managers see the decesion making skill more important for senior managers to practice in Chinese SOCs.

(5) Quality Control refers to a skill of establishing standards for high quality products and services, and to exercise strong control for achieving and maintaining them. Low quality of products is a big problem in Chinese SOCs. They are hurting the Chinese managers and consumers very much. In order to imporve the product quality, Chinese industrial management system has introduced Total Quality Control (TQC) and other methods from Japan and Western countries for the last two decades. Almost every SOCs has carried out activities of TQC and QCC (Quality Control Circle). As a result, the quality of products made in China is gradually improving, although there still remain some problems. Thus, the skill of quality control was chosen as the fifth important one (26.2\%) in Chinese SOCs.

(6) System Development means introducing necessary rules and procedures to get jobs done effectively. Warner (1995) noted that when the mass of 1.2 billion people are not mobilized effectively or mismanaged, they constitute a major impediment to development and progress. This explains why Dr. Yat-sen Sun, founder of the Chinese Republic in 1911, once described the Chinese to be like a 'heap of loose sand.' Warner 
pointed out that when the mass can be developed and harnessed to work cooperatively, they can become the nation's greatest source of strength, both politically and economically. Before the economic reform, employee relations were in a state of disunity for the most of Chinese SOCs. Most managers used the method of 'Theroy $\mathrm{X}$ ' (bureaucratic, top-down methods) to solve this problem. Organizational changes taken place since the start of the economic reform have encouraged Chinese managers to adopt the method of 'Theory Y.' Now, many Chinese managers in SOCs have realized the importance of utilizing employees' power and initiatives for system development in SOCs.

(7) Motivatng Skill indicates encouraging others to challenge difficult tasks, creating enthusiasm among employees, and supporting their achieving behavior. This skill was selected to be the 7 th important one (21.9\%) for Chinese managers to have in SOCs. China is facing a complex set of dilemmas in its efforts toward development of economy. One of the most difficult dilemmas now confronting the Chinese socialist economy is how to attain economic development, while diffusing social discontent with the widening disparity in incomes and standards of living between the haves and the have-nots (Warner, 1995). Traditional management system based on the philosophy of an 'iron rice bowl' tends to encourage lax practices regarding wage and bonus distribution. Employees enjoy eating food in a 'big rice-pot,' allowing every employee to get nearly the equal amount of his / her salary and bonus regardless of performance. In order to change this practice, as Antoniou and Whitman (1995) proposed, a more serious consideration must be given to the issue of motivation based on the individual's preference for specific work related rewards. Chinese managers in SOCs started to used motivating methods based both on intrinsic and extrinsic incentive mechanisms. These methods were mainly introduced from Western countries to enhance employee work motivation and job satisfaction (e.g. Engholm, 1990). The motivation systems used in Chinese SOCs consist of a variety of incentive practices: a comprehensive reward system, a grade reward system, a hundred-mark reward system, an incentive reward for excess production, a piecework system, a contracting out system, and a floating salary and bonus system (Wu and Chen, 1992). However, the issue of employee motivation has become a great concern in managing SOCs, because of its administrative difficulties. The statistical analysis on frequencies of choosing a motivating skill as the most important one indicated a significant difference among managers: the top (30.8\%), middle (22.2\%) and lower-middle (13.6\%) managers reported differential support with this skill showing a significant difference between the top and lower-middle managers $(\mathrm{Z}=2.20, \mathrm{P}<.05)$. It seems that the top managers think the motivating skill is more important for themselves than the middle and lower-middle managers think it to be for their superior managers.

(8) Innovativeness is explained in the questionnaire to be a skill of going beyond the status quo and implementing new ideas. Overall, this skill represented the 8th important one (19.5\%) for managers in Chinese SOCs to practice. To catch up with the advanced method of management practiced in Japan and Western countries, Chinese managers must change their traditional management styles to morden ones. The result shows that the Chinese managers become aware of the importance of innovativeness as a way to break the traditional practices. This skill will help the organization develop new products and services, and implement the new ideas into practice (Worren and Koestner, 1996). The statistical analysis on the frequencies of choosing innovativeness as the most important skill showed a significant difference between the managers in high (9.3\%) and low (23.1\%) performing SOCs $(\mathrm{Z}=2.21, \mathrm{P}<.05)$. Managers in the low performing SOCs supported the innovativeness more than those in the high performing SOCs, probably because the innovativeness is more in need in the low performing SOCs.

(9) Planned Action refers to a skill of developing short- and long-term plans and executing 
one's job by following the plan. Overall, there were $16.7 \%$ (9th) managers who chose this skill as one of the five important skills for their superior managers to have. It was mentioned earlier that employees in Chinese SOCs were ununited like a 'heap of loose sand.' Thus, the managers must utilize the skill of system development to solve this problem. Traditionally, managers in Chinese SOCs tended to do their jobs based on their own personal preference under the policy guidelines given by the government rather than on the plans discussed and decided in their own corporation. But now, they are aware of the importance of improving their skill of planned actions which enable them to manage their corporations by following the short- and long-term plans for goal attainment.

(10) Integrity means showing sound thoughts and ethics, and behaving in consistent with principles, beliefs and values of the community. The integrity was given the last position (15.2\%) within the ten most important skills for Chinese managers in SOCs. Before the economic reform, there were minimum corporate principles, beliefs and values. Thus, the integrity of managers was rarely asked except for showing strong royalty to the socialist government. Since 1980s, corporate culture that sets key values and missions for the corporation has acquired an important function for the effort of organizational development in Chinese SOCs (Wakabayashi and Lu, 1993). The theory of corporate culture, especially the one based on 'Theory-Z,' emphasizes the importance of managerial ideology and philosophy unique to the individual corporation (Ouchi, 1981; Peters and Waterman, 1982; Wakabayashi and Lu, 1993). In order to establish the value system for the corporations, and to pronounce them to employees and customers in sound and visual ways, managers in Chinese SOCs must to learn how to identify themselves with their corporate value systems, and to demonstrate their personal integrity.

Among the ten most important skills discussed above, six skills, namely strategic thinking, profit consciousness, decision making, system develop- ment, motivating and innovativeness were found belonging to the organizational development factor identified and labelled as such by Chen (1996) based on the factor analytic study on the data regarding opportunities to use managerial skills in Chinese SOCs. The rest of skills were categolized into either one of the remaining factors, organizational goal attainment, team work and technical skills. As Bowles and Riles (1988) pointed out, one of the critical organization issues is to identify with, motivate toward, and retain goals to achieve top level corporate performance. The result of this study also indicated that the Chinese managers in SOCs consider the skills of organizational developmant to be most important for improving organizational performance.

\section{2 ) Ten most needed skills for improving the present level of managerial performance}

We have discussed the ten most important managerial skills which are now used and associated with the present level of managerial performance in Chinese SOCs. Now, we turn to the ten most needed skills for Chinese managers for improving their managerial performance on the present job. Results for this question were found basically the same as the important 'present skills' discussed earlier. However, there exist some differences between the two responses. Table 2 shows the ten most needed skills for improving the present level of performance.

As shown in Table 2, almost the first 7 most needed skills are the same as the present most important skills listed in Table 1, although ranks were slightly different: namely strategic thinking (43.3\%, rank 1), proper use of personnel $(40.5 \%$, rank 2), decision making (31.4\%, rank 3), motivating (27.6\%, rank 4), innovativeness (26.7\%, rank 5), quality control (23.8\%, rank 7) and profit consciousness $(18.6 \%$, rank 9$)$. It was found that motivating and innovativeness skills improved rankings relative to those in Table 1 , indicating that the managers in Chinese SOCs paid more attention to these skills for improving the performance, while the profit cinsciousness dropped from rank 2 to rank 9 . Strategic thinking, proper 
Table 2 The first 10 most frequently cited managerial skills for Chinese managers in SOCs, chosen in order of importance (from rank 1st to 5th) for improving their managerial performance on the present job

$\mathrm{N}=210$

\begin{tabular}{l|c|c|c|c|c|c|c|c}
\hline \hline \multirow{2}{*}{ No. Skill } & \multirow{2}{*}{$\begin{array}{c}\text { Overall } \\
\text { Ranking }\end{array}$} & $\begin{array}{c}\text { Overall } \\
\text { Fre- } \\
\text { quency }\end{array}$ & \multirow{2}{*}{$\%$} & \multicolumn{4}{|c}{ Frequencies by Importance Rank } \\
\cline { 5 - 9 } & 1 & 91 & 43.3 & 75 & 7 & 4 & 3 & 2 \\
\hline 1 Strategic thinking & 2 & 85 & 40.5 & 13 & 11 & 16 & 11 & 34 \\
37 Proper use of personnel & 3 & 66 & 31.4 & 32 & 16 & 9 & 4 & 5 \\
3 Decision making skills & 4 & 58 & 27.6 & 3 & 10 & 28 & 9 & 8 \\
15 Motivating skills & 5 & 56 & 26.7 & 13 & 17 & 13 & 7 & 6 \\
4 Innovativeness & 6 & 53 & 25.2 & 8 & 12 & 6 & 10 & 17 \\
28 Technical expertise & 7 & 50 & 23.8 & 4 & 3 & 11 & 16 & 16 \\
32 Quality control & 8 & 48 & 22.9 & 3 & 11 & 10 & 14 & 10 \\
17 Creativity development & 9 & 39 & 18.6 & 4 & 5 & 12 & 11 & 7 \\
31 Profit consciousness & 10 & 38 & 18.1 & 1 & 3 & 1 & 12 & 21 \\
36 Fare treatment & &
\end{tabular}

use of personnel and decision makimg remained unchanged, as being the first three most important skills between the two Tables. A test of comparisons of overall frequencies between the high and low performing SOCs produced a significant difference only on the strategic thinking skills: $29.6 \%$ and $48.1 \%$ for high and low performing SOCs respectively $(\mathrm{Z}=2.37, \mathrm{P}<.05)$. This result indicates that managers in low performing SOCs are more in need for the strategic thinking skill for impriving their managerial performance than those in high performing SOCs. In addition to the above 7 skills, the following 3 skills were found to be unique to the most needed skill category for managers in Chinese SOCs.

(1) Technical Expertise means demonstrating up-to-date knowledge in industry, and establishing oneself as an expert in the profession. This skill was found to be the 6th (25.2\%) needed skill for Chinese managers for improving their performance. Since the up-to-date managerial and technical knowledge is in short supply in China, managers quite naturally came to realize the need for acquiring thchnical expertise for improving their job performance.

(2) Creativity Development refers to skills for stimulating subordinates to initiate improve- ments and for supporting innovative thinking. This constituted the 8th needed skill (22.9\%) for Chinese managers. The skill of creativity development is similar to the innovativeness. Both of them are related to the process of innovation which will determine the 'tommorrow' of corporate prosperity.

(3) Fair Treatment refers to a skill of treating one's subordinates in a fair manner, and providing equal support and encouragement to all group members. This skill becomes the 10th needed one (18.1\%). In Chinese SOCs, if a manager wants to stimulate mativation among subordinates, he must provide equal treatment, because of the very strong egalitarian sentiment prevailing among Chinese workers. This tendency may be stronger in the traditional Chinese workplace. A statistical analysis showed significant differences between the top $(25.0 \%)$ and middle $(8.1 \%)$ managers $(\mathrm{Z}=2.73, \mathrm{P}<.05)$, and between the middle and lower-middle (22.0\%) managers $(\mathrm{Z}=2.36, \mathrm{P}<.05)$ regarding the fair treatment. These resultes indicate that the middle managers are the least egalitarian-oriented, relative to the top and lowermiddle managers.

The above 3 needed managerial skills were found replacing skills for system development, 
planned actions and integrity listed in Table 1 as important skills now in practice. Thus these three needed skills are expected to be pivotal for Chinese managers to improve their present job performance in SOCs.

\section{3) Ten most important skills needed for man- aging market oriented economy}

Next, the ten most important managerial skills to enable Chinese managers to function effectively under the market economy will be discussed. This group of skills were expected to be different from the previous two, but the results shown in Table 3 indicate there are 8 skills overlapping with those shown in Table 1. Namely, in terms of overall frequencies, strategic thinking (74.3\%, rank 1), proper use of personnel (58.6\%, rank 2), profit consciousness (41.4\%, rank 3 ), quality control (37.1\%, rank 4), decision making (32.4\%, rank 5), innovativeness (29.5\%, rank 6), motivating (21.4\%, rank 7) and planned actions (13.3\%, rank 10) were found being cross-listed in two tables. Among these skills, quality control and innovativeness increased rankings, indicating that the managers in Chinese SOCs think these skills are getting more important in market-oriented economy. Statistical analyses showed significant differences in four different aspects as follows. (1)
On strategic thinking, a difference was found between the managers in the high $(61.1 \%)$ and low (78.8\%) performing SOCs $(Z=2.57, \mathrm{P}<.05)$. This result indicates that the strategic thinking skill is considerd to be more important for the managers in low performing SOCs than those in high performing SOCs to function effectively under the market economy environment. (2) Regarding the skill of quality control, differences were found between the top (51.9\%) and middle (33.3\%) managers $(Z=2.22, P<.05)$, and between the top and lower-middle $(30.5 \%)$ managers $(\mathrm{Z}=2.29, \mathrm{P}<.05)$. This result indicates that the top managers think the quality control skill is more important in market-oriented economy than the middle and lower-middle managers. (3) On the decision making skills, a difference was found between the middle $(24.2 \%)$ and lower-middle $(47.5 \%)$ managers $(Z=3.02, P<.01)$, indicating that the lowermiddle managers think the decision making skill is getting more important than do the middle managers to prepare for the market economy. (4) Finally, a significant difference was found on the motivating skill between the top (28.8\%) and lower-middle (13.6\%) managers $(\mathrm{Z}=1.97, \mathrm{P}<.05)$. This result explains that the motivating skill is considered more important by top managers than lower-middle managers when dealing with the

Table 3 The first 10 most frequently cited managerial skills for Chinese managers in SOCs, chosen in order of importance (from rank 1st to 5th) for functioning effectively under the market economy situations $\mathrm{N}=210$

\begin{tabular}{|c|c|c|c|c|c|c|c|c|}
\hline \multirow{2}{*}{ No. } & \multirow{2}{*}{$\begin{array}{c}\text { Overall } \\
\text { Ranking }\end{array}$} & \multirow{2}{*}{$\begin{array}{c}\text { Overall } \\
\text { Fre- } \\
\text { quency }\end{array}$} & \multirow{2}{*}{$\%$} & \multicolumn{5}{|c|}{ Frequencies by Importance Rank } \\
\hline & & & & 1 st & 2 nd & $3 \mathrm{rd}$ & 4 th & 5 th \\
\hline 1 Strategic thinking & 1 & 156 & 74.3 & 137 & 9 & 6 & 2 & 2 \\
\hline 37 Proper use of personnel & 2 & 123 & 58.6 & 11 & 21 & 28 & 17 & 46 \\
\hline 31 Profit consciousness & 3 & 87 & 41.4 & 8 & 6 & 24 & 27 & 22 \\
\hline 32 Quality control & 4 & 78 & 37.1 & 1 & 11 & 14 & 34 & 18 \\
\hline 3 Decision making skills & 5 & 68 & 32.4 & 8 & 41 & 14 & 4 & 1 \\
\hline 4 Innovativeness & 6 & 62 & 29.5 & 6 & 27 & 9 & 15 & 5 \\
\hline 15 Motivating skills & 7 & 45 & 21.4 & 0 & 2 & 22 & 11 & 10 \\
\hline 17 Creativity development & 8 & 37 & 17.6 & 0 & 5 & 11 & 11 & 10 \\
\hline 2 Problem identification & 9 & 32 & 15.2 & 7 & 16 & 2 & 3 & 4 \\
\hline 5 Planned actions & 10 & 28 & 13.3 & 1 & 10 & 7 & 4 & 5 \\
\hline
\end{tabular}


situation of socialist market economy.

In addition to the above 8 skills, two other skills were chosen as being uniquely important for functioning effectively under the market economy as follows.

(1) Creativity Development refers to a skill for stimulating subordinates to initiate improvements and supporting innovative thinking. This skill was found to be the 8th important (17.6\%) for managers in Chinese SOCs to function effectively under the market economy. As was said before, this skill will impact on corporate performance of the future through the enhanced creative thinking.

(2) Problem Identification means anticipating future problems, and investigating causes and possible consequences. Overall, this skill was chosen by Chinese managers (15.2\%) to be the 9 th important one. Development of market economy requires managers to sense the changes in the corporate envirnment, and discoverring and working with future problems. Thus, the problem identification skill was considered important for Chinese managers to work effectively in the market economy to come.

Since China introduced the socialist market economy system in 1992, the business environment has been changed to have more uncertainty and competitiveness. To deal with this situation, managers in Chinese SOCs have been forced to change the traditional management systems into morden ones, since technology and the nature of work have changed and management roles have changed also (Bowles and Riles, 1988). Thus, creativity development and problem identification skills are expected to become very important for Chinese managers in SOCs to perform effectively under the market economy environment.

\section{CONCLUDING REMARKS}

For this study, an effort was made to identify top ten managerial skills to be important for managers in Chinese SOCs under three different circumstances. Namely ten most important skills for: (1) characterising the present level of managerial performance, (2) being needed for improving managerial performance on the present job, and (3) being considered to be most important to function effectively under the market economy situations. As Table 4 indicates, exactly the same seven skills constitute the importnat skill category

Table 4 Summary results of the first 10 most frequently cited managerial skills for managers in Chinese SOCs shown in Table 1 to 3 for 3 different situations

\begin{tabular}{|c|c|c|c|c|c|c|c|c|c|c|c|c|}
\hline \multirow[t]{2}{*}{ No. } & \multicolumn{3}{|c|}{$\begin{array}{c}\text { Now Practiced } \\
\text { Overall }\end{array}$} & \multicolumn{3}{|c|}{$\begin{array}{l}\text { Needed } \\
\text { Overall }\end{array}$} & \multicolumn{3}{|c|}{$\begin{array}{l}\text { Market } \\
\text { Overall }\end{array}$} & \multicolumn{3}{|c|}{$\begin{array}{c}\text { Total } \\
\text { Overall }\end{array}$} \\
\hline & $\mathrm{R}$ & Fr. & $\%$ & $\mathrm{R}$ & Fr. & $\%$ & $\mathrm{R}$ & Fr. & $\%$ & $\mathrm{R}$ & Fr. & $\%$ \\
\hline 1 Strategic thinking & 1 & 97 & 46.2 & 1 & 91 & 43.3 & 1 & 156 & 74.3 & 1 & 334 & 53.0 \\
\hline 31 Profit Consciousness & 2 & 80 & 38.1 & 9 & 39 & 18.6 & 3 & 87 & 41.4 & 3 & 206 & 32.7 \\
\hline 37 Proper use of personnel & 3 & 78 & 37.1 & 2 & 85 & 40.5 & 2 & 123 & 58.6 & 2 & 286 & 45.4 \\
\hline 3 Decision making skills & 4 & 65 & 31.0 & 3 & 66 & 31.4 & 5 & 68 & 32.4 & 4 & 199 & 31.6 \\
\hline 32 Quality control & 5 & 55 & 26.2 & 7 & 50 & 23.8 & 4 & 78 & 37.1 & 5 & 183 & 29.0 \\
\hline 7 System development & 6 & 47 & 22.4 & 11 & 34 & 16.2 & 12 & 26 & 12.4 & 9 & 107 & 17.0 \\
\hline 15 Motivating skills & 7 & 46 & 21.9 & 4 & 58 & 27.6 & 7 & 45 & 21.4 & 7 & 149 & 23.6 \\
\hline 4 Innovativeness & 8 & 41 & 19.5 & 5 & 56 & 26.7 & 6 & 62 & 29.5 & 6 & 159 & 25.2 \\
\hline 5 Planned actions & 9 & 35 & 16.7 & 11 & 34 & 16.2 & 10 & 28 & 13.3 & 10 & 97 & 15.4 \\
\hline 26 Integrity & 10 & 32 & 15.2 & 22 & 18 & 8.6 & 21 & 15 & 7.1 & 17 & 65 & 10.3 \\
\hline 28 Technical expertise & 19 & 20 & 9.5 & 6 & 53 & 25.2 & 14 & 23 & 11.0 & 11 & 96 & 15.2 \\
\hline 17 Creativity development & 13 & 29 & 13.9 & 8 & 48 & 22.9 & 8 & 37 & 17.6 & 8 & 114 & 18.1 \\
\hline 36 Fare treatment & 13 & 29 & 13.9 & 10 & 38 & 18.1 & 15 & 22 & 10.5 & 13 & 89 & 14.1 \\
\hline 2 Problem identification & 13 & 29 & 13.9 & 14 & 31 & 14.8 & 9 & 32 & 15.2 & 12 & 92 & 14.6 \\
\hline
\end{tabular}


across these three different circumstances: i.e., strategic thinking, profit consciousness, proper use of personnel, decision making, quality control, motivating, and innovativeness skills. Although the order of importnace differed slightly, the above results imply that the core set of skills for Chinese managers for the above three situations remains basically the same. It can be said that these seven skills are very important for Chinese managers at present and in the future also. However, in different situations, a different set of skills were found important. For the present job performance, three unique skills were chosen among the top ten: skills of system development, planned actions and integrity. On the other hand, skills of technical expertise, creativity development and fare treatment were chosen as uniquely needed to improve present performance. Likewise, skills of creativity development, problem identification and planned action were chosen as uniquely important for the future market-oriented economy.

It is interesting to note that the most of top ten skills belong to the organizational development factor as identified by factor analytic method (Chen, 1996). It is hoped that Chinese managers in SOCs become experts in organizational development of their corporations by acquiring a set of skills identified by this study, so that they can manage the process of organizational changes that will be needed to cope with the current business environment that is changing quite rapidly.

\section{REFERENCES}

Antoniou, Peter H. and Katherine Whitman (1995) Work Related Values of Chinese Managers in the People's Republic of China, Journal of Asian Business, Vol. 11, No. 1.

Bartunek, J.M., C.A. Lacey and D.R. Wood (1992) Social Cognition in Organizational Change: An Inside-outside Approach, Journal of Applied Behavioral Science, 28: 204-223.

Bowles, Valerie B. and Arthur R. Riles, Jr. (1988)

Work Place Challenges for Managers in the
Twenty-first Century, in Niehaus, Richard J. and Karl F. Price (eds) Creating the Competitive Edge through Human Resource Applications, New York, Plenum Press.

Brown, D.H. and Jackson, M. (1991) Meeting the Challenge to Provide Effective Managers in the Changing Chinese Envirronment, in Campbell, N. and Brown, D.H. (eds), Advances in Chinese Industrial Studies, Vol. 2, Greenwich, CT: JAI Press.

Brown, David H. and Mohamed Branine (1995) Managing people in China's foreign trad ecorporations: some evidence of change, The International Journal of Human Resource Management 6:1.

Caligiuri, Paula M. and Linda K. Stroh (1995) Multinational corporation management strategies and international human resources practices: bringing IHRM to the bottom line, The International Journal of Human resource Management, Vol. 6, No. 3 .

Chen, Ziguang (1993 a) The differences in Cognition of Top Managers' Leadership Types in Chinese Enterprises: On Cognitive Differences among Top Managers, Middle Managers and Technicians, Japanese Journal of Administrative Behavior, 8(2): 107-112.

Chen, Ziguang (1993 b) The Differences in Estimation of Interpersonal Relations and the Importance of Intellectuals among Three Kinds of People in Enterprises, Acta Psychology Sinica, Vol. 25, No. 1.

Chen, Ziguang and Mitsuru Wakabayashi, (1996a) Decentralized Decision Making Practices in Chinese State-Owned Corporations, Japanese Journal of Administrative Behavior, 10(2): 79-94.

Chen, Ziguang (1996) Managerial Skill Formulation in Chinese State-Owned Corporations: Focusing on the Leader-Member Exchange Relation as a Facilitator for Skill Learning Forum of International Development Studies, 6, 217-236.

Child, J. (1987) Enterprise Reform in ChinaProgress and Problems, in Warner, M. (ed), Management Reforms in China, London: 
Pinter, pp. 24-52.

Child, J. (1991) A Foreign Perspective on the Management of People in China, The International Journal of Human Resource Management, 2(1): 93-107.

Child, J. (1994) Management in China in the age of Reform, Cambridge: Cambridge University Press.

Child, John, and Yuan Lu (1990) Industrial Decision-Making under China's Reform, 1985-1988, Organization Studies, 11: 321-351.

Guanghaw, Y. (1985) Employment Wages and Social security in China, International Labour Review, 124(5): 411-22.

Han, J. and Morishima, M (1992) Labour System Reform in China and its Unexpected Consequences, Economic and Industrial Demoncracy: An International Journal, 13: 233-61.

Heller, Frank A. (1989) The Under-utilization of Competence in British Management, in B.J. Fallon, H.P. Pfister and J. Brebner (eds) Advances in Industrial Organizational Psychology, Amsterdam: Elsevier Science Publishers BV North Holland.

Hu, T. et al. (1988) Analysis of Wages and Bonus Payments among Tianjin Urban Workers, The China Quality, 133: 76-93.

Lau, Chung-Ming and Richard W. Woodman (1995) Understanding Organizational Change: A Schematic Perspective, Academy of Management Journal, Vol. 38, No. 2, 537-554.

Lee, L.T. (1986) Trade Unions in China: from 1949 to the Present, Singapore: Singapore University Press.

Li, Yiwen (1996) The Reform of Chinese Stateowned Enterprises: The Problem and a Future Perspective, Forum of International Development Studies, 4: 125-141.

Littler, C.R. and Lockett, M. (1983) The Significance of Trade Unions in china, International Relations Journal, 14(4): 31-42.

Lu, Y. and J. Child (1994) Decentralisation of Decision Making in China's State Enterprises', paper presented at the Congerence on Management Issues for China in the 1990s, St
John's College, Cambridge, 23-5 March.

Ouchi, W.G. (1981) Theory Z, Reading Mass.: Addison-Wesley.

Peters, T.G. and R.H. Waterman (1982) In search of excellence, New York: Harper \& Raw.

Sun, Gang and Mitsuru Wakabayashi (1992) The management development of a large company group in China: A case study of Honko Steel Manufacturing Group, Japanese Journal of Administrative Behavior, 7(2): 103-113.

The Central Committee of China's Communist Party, (1995) Suggestions of Establishing the 9th Five-year Plan for the National Economy and Social Development, and the Objectives in 2010, the People's Daily Overseas Edition, 5th, October.

Wakabayashi, Mitsuru and Shengzhong Lu (1983) Creation of New Corporate Culture and Development of the Organization: A Study on the Process of Corporate Culture based on Observations in Japanese and Chinese Corporations, Japanese Journal of Administrative Behavior, 8(2):133-45.

Wakabayashi, Mitsuru and Xiaoqi Zhen (1995) Historical Development of Chinese Management Reform Practices and the Administrative Behavior Research, Japanese Journal of Administrative Behavior, 10(1): 1-22.

Wang, Zhongming (1989) Participation and Skill Utilization in Organizational DecisionMaking in Chinese Enterprises, in B.J. Fallon, H.P. Pfister and J. Brebner (eds.), Advances in Industrial Organizational Psychology, pp.19-26, Amsterdam: Elsevier Science Publishers BV.

Warner, M. (1985) Training China's Managers, Journal of General Management, 11(2): 12-26.

Warner, M. (1987) China's Managerial Training Revolution, in Warner, M. (ed.) Management Reforms in China. London: Frances Pinter.

Warner, M. (1991) Labour-Management Relations in the People's Republic of China: the Role of the Trade Unions, The international Journal of Human Resource Management, 2: 205-20.

Warner, M. (1992) How Chinese Managers Learn, London: Macmillan.White, G. (1982) Urban 
Employment and Labour Allocation Policies in Post-Mao China, World Development, 10(8): 613-32.

Warner, Malcolm (1995) The Management of Human Resources in Chinese Industry, Basingstoke, Macmillan.

Whit, G. (1987) Labour Market Reform in Chinese Industry, in Warner, M. (ed.) Management Reforms in China, London: Frances Pinter, pp. 113-26.

Wise, Richard E. and Robert S. Feen (1988) Identifying Future Management Development Needs, in Richard J. Niehaus and Karl F. Price (eds.), Creating the Competitive Edge through Human Resource Applications, New York and London: Plenum Press.

Worren, Nicolay A.M. and Richard Koestner
(1996) Seeking innovating team players: Contextual Determinants of Preferred Applicant Attributes, The international Journal of Human Resource Management, 7:2.

Wu, Liangliang and Ziguang Chen (1992) A Study on Means of Corporation Material Motivation and its Effect, Chinese Journal of Applied Psychology, Vol. 7, No. 4.

Zheng, H.R. (1987) An Introduction to the Labour Law of the People's Republic of China, Harvard International Law Journal, 28(2): 385431.

Zhong, Yeqing, (1993) Humam resources management in Chinese-Japanese joint venture companies, Japanese Journal of Administrative Behavior, 8(1):55-62.

(平成 8 年 11 月 15 日受稿, 平成 8 年 12 月 5 日受理)

\section{APPENDIX}

\section{Discriptions of the 37 managerial skills}

1. Strategic Thinking: considers market situations, competitors, future goals and long-term company prosperity, when making decisions.

2. Problem Identification: anticipates future problems and investigates causes and possible consequences.

3. Decision Making Skills: makes timely decisions under uncertainty and risk-involved situations.

4. Innovativeness: goes beyond the status quo and implement new ideas.

5. Planned Actions: develops short- and long-term plans and executes one's jobs by following the plan.

6. Team Building Skills: builds a strong team with effective team structure for the action.

7. System Development: introduces necessary rules and procedures to get jobs done effectively.

8. Process Control: watches to maintain undisrupted task processes, and rewards orderly behaviors and reprimands misconduct when necessary.

9. Delegation: assigns responsibilities, delegates authorities and provides resources to let others excute task requirements.

10. Prividing Structure: provides clear goals and priorites, and clrarifies roles and responsibilities for each person.

11. Initiative: addresses difficult tasks and takes personal responsibility to complete the tasks.

12. Presenting Missions: develops missions and common visions for the work group, and encourages others to carry out the missions.

13. Persuasiveness: states own ideas and persuades others to take necessary actions by following the ideas.

14. Teamwork: solves problems and enhances communization within the team to foster collaboration among team members.

15. Motivatng Skills: encourages others to challenge difficult tasks, creates enthusiasm in others, and supports achieving behaviors. 
16. Developing Subordinates: provides new assignement to broaden subordinate's task performing skills and coach them to learn skills.

17. Creativity Development: stimulates subordinates to initiate improvements and supports innovative thinking.

18. Network Building Ability: develops relationships with key people inside and outside the organization, and use them to get things done.

19. Performance Evaluation: evaluates each person's contribution objectively and gives feedback accordingly.

20. Consensus Building Skills: encourages others to share common ideas by promoting mutual understanding and conflict resolution.

21. Listening Skills: creates an atmosphere for open dialogue, encourages others to talk, and pays attention for the in-depth understanding.

22. Communication Skills: conveys information effectively by orally presenting in front of a group.

23. Positive Action: tasks immediate and independent action whenever needed, and takes a leadership role to help accomplish group goals.

24. Work Commitment: establishes high performance goals and demonstrates hard work to achieve them.

25. Achievement Motive: shows strong willingness to get results and persists despite obstacles to achieve the final success.

26. Integrity: shows sound thoughts and ethics, and behaves in a consistent way among principles, beliefs and values.

27. Flexibility: can adjust to multiple demands, shift priorities, and cope with constraints and oppositions adequately.

28. Technical Expertise: demonstrates up-to-date knowledge in industry and establish oneself as an expert in the profession.

29. Managing by Quantitative Data: establishes numerical goals, sets budget, monitors the process by using quantitative information.

30. Sensing Environmental Changes: collects information for sound business judgements about changes in government, social and market conditions.

31. Profit Consciouness: emphasises the profit targets, and stresses cost-saving and profit-making behaviours.

32. Quality Control: establishes standards for high quality products and services, and exercises strong control for realizing them.

33. Sensitivity to Customer Needs: tries hard to meet customer needs and looks for better ways to increase customer satisfaction.

34. Organizational Commitment: shows commitment to company goals, and keeps personal goals and values aligned with those of the company.

35. Group Membership Skills: puts group goals ahead of personal ones and contributes to achieving group goals collaborating with others.

36. Fair Treatment: treats your subordinates in a fair manner, and provides equal support and encouragement to all group members.

37. Proper Use of Personnel: chooses the right person for the right job based on the accuarte assessment of each subordinate's ability. 